\title{
Friction and wear studies on the temperature dependence of brake-pad materials containing brass
}

\author{
Fatima Eddoumy ${ }^{1,4}$, Haytam Kasem¹, Philippe Dufrenoy ${ }^{1,2,4}$, Jean-Pierre Celis ${ }^{3}$, \\ and Yannick Desplanques ${ }^{1,2,4}$
}

${ }^{1}$ CNRS, UMR 8107, 59650 Villeneuve d'Ascq, France

2 USTL, LML, 59650 Villeneuve d'Ascq, France

${ }^{3}$ KU Leuven, Dept. MTM, Kasteelpark Arenberg 44, 3001 Leuven, Belgium

${ }^{4}$ Univ Lille Nord de France, 59000 Lille, France

\begin{abstract}
Brake pad materials for automobile applications are basically polymer matrix composites. Various reinforcing constituents used in brake pads are organic, metallic and ceramic fillers which play among others an important role on the mechanical and thermal properties, and the wear resistance at high temperature. Friction and wear depend on various parameters such as the micro-chemical structure of the pad and of the metallic counter-face, the rotation speed, the pressure, and the contact surface temperature (M.G. Jacko 1983). This latter parameter can be locally as high as 600 up to $1.500^{\circ} \mathrm{C}$ depending on the brake type (M.G. Jacko 1983; Blau 2001). Thermal models have been developed to study interface effects at contacting surfaces (Majcherczak, Dufrenoy et al. 2007). Frictional energy can be dissipated through different mechanisms such as oxidation, rise in temperature, formation of wear particles, entropy changes associated to viscoelastic and viscoplastic deformation, and noise generation (Eddoumy, Addiego et al. 2011). Studies of friction brake show that more than $95 \%$ of the dissipated energy is transformed into heat (Kasem, Thevenet et al.; Majcherczak, Dufrenoy et al. 2007). Thermal analysis is therefore a primordial step in the study of brake systems since it provides thermo-mechanical properties (Majcherczak, Dufrenoy et al. 2007). The influence of the addition of metallic fibers on the performance of organic friction composites has been investigated using friction tests (Qu, Zhang et al. 2004). Benefits or limitations of the different fibers have been reported, however the issues of thermomechanical properties or effect of temperature on friction and wear behavior were not yet investigated (Bijwe, Kumar et al. 2008). No effort was done to correlate the thermo-mechanical and thermal properties with the friction and wear behavior. An important prerequisite is to get a good understanding on how brake materials behave. However, a link between thermal transitions and tribological behavior occurring at different temperatures is still missing.
\end{abstract}

This investigation is focused on the effect of thermal properties of brass-free and brass containing brake pad composites on their friction and wear behavior to analyze the benefit of brass addition. Hereto, the impact of the incorporation of brass into the composites on their degradation was determined from TGA measurements. In a second step, heat transfer and thermal diffusivity were determined with hot disk to study the effect of brass on the thermal transport properties of brake pad composites. Friction and wear behavior were investigated under reciprocating sliding performed at room temperature (RT) up to $400^{\circ} \mathrm{C}$. The coefficient of friction and the dissipated energy were analyzed for both brass-free and brass containing composites. The observation of the wear track enabled us to suggest a possible relationship between the thermal and mechanical properties on one side, and the friction and wear behavior on the other side.

TGA results indicate that thermal decomposition pathway of the brass-free composite and one containing brass are quite similar. Hot disk measurements showed that the heat transfer significantly improved in the presence of brass. However, the presence of brass induces a significant decrease of the storage modulus of the composite. Experimental results obtained show that brass particles decrease the wear resistance of the composite at room temperature. In an attempt to establish how the brass acts positively on the friction and wear performance of brake pad materials, the microstructure before, during and after sliding tests was investigated. A poor interaction was observed between brass and matrix what probably leads to a reduction of friction and wear resistance at room temperature. At higher temperature, brass containing composite exhibits a lower wear track depth. The enhancement of wear resistance of the brass containing composite was attributed to the better heat transfer in comparison with a brass-free composite.

The present research work has been supported by International Campus on Safety and Intermodality in Transportation, the NordPas-de-Calais Region, the European Community, the Regional Delegation for Research and Technology, the Ministry of Higher Education and Research, and the National Center for Scientific Research. The authors gratefully acknowledge the support of these institutions.

\section{References}

Bijwe, J., M. Kumar, et al. (2008). "Optimization of brass contents for best combination of tribo-performance and thermal conductivity of non-asbestos organic (NAO) friction composites.” Wear 265(5-6): 699-712.

Blau, P. J. (2001). "Compositions, functions and testing of friction brake materials and their additives." Oak Ridge National Laboratory Technical Report ORNL/TM-2001. 
Eddoumy, F., F. Addiego, et al. (2011). "Reciprocating sliding of uniaxially-stretched ultra-high molecular weight polyethylene for medical device applications." Wear 272(1): 50-61.

Kasem, H., J. Thevenet, et al. "An emissivity-corrected method for the accurate radiometric measurement of transient surface temperatures during braking." Tribology International 43(10): 1823-1830.
M.G. Jacko, S. K. R. (1983). "Encyclopedia of Composite Materials and Components." John Wiley: p.144.

Majcherczak, D., P. Dufrenoy, et al. (2007). "Tribological, thermal and mechanical coupling aspects of the dry sliding contact." Tribology International 40(5): 834-843.

Qu, X., L. Zhang, et al. (2004). "The effect of steel fiber orientation on frictional properties of asbestos-free friction materials.” Polymer Composites 25(1): 94-101. 